\title{
The Concept of an Eco-Efficient Regional Development Strategy: A Case of the Baikal Region
}

\author{
By Karina Gunzenova ${ }^{1 *}$
}

\begin{abstract}
The transition to sustainable development requires a comprehensive systematic state policy and suggests a change in existing cultural characteristics that determine the nature of the economic development of society. It assumes reliance on effective mechanisms that can minimize the time and risks of possible destructive processes of such a transition. As a mechanism for institutionalization, we propose using the concept of ecological efficiency as a criterion for the compliance of strategic development plans and relevant regulatory legal acts with the selected course of sustainable development. This work aims to disclose the concept of eco-efficiency through understanding the benefits of focusing on qualitative development criteria. The methodological basis of the study was the provisions of dialectical realism, which determines the variability of the content of quantitative development indices with the constancy of qualitative guidelines, thus ensuring balanced development of civilization for an indefinitely long term.
\end{abstract}

Keywords: sustainable development, ecological efficiency, sustainable development strategy, Baikal region, dialectical realism

\section{Introduction}

The current vector of civilizational development implies that the living standards of the population are in correlation with the gross domestic product (which is interconnected with an increase in production and consumption). This leads to depletion of natural resources, an increase in the man-made burden on the ecosystem, capitalist relations, and the formation of conditions for social disparities.

The concept of sustainable development presupposes economic growth by increasing the resource efficiency (secondary resources, a closed consumption cycle, resourcesaving technologies), the development of green technologies, and ensuring that the interests of various sectors of society are appropriately addressed.

The transition from the previously existing technocratic strategy to the relevant concept of sustainable development requires an integrated approach given the peculiarities of the formation of worldview and value foundations in society. Regardless of all their progressiveness, the developed indices that reflect quantitative indicators face two problems: the underestimation of all interrelated factors and, as a consequence, the inadequacy of the final indicator of actual reality.

It is possible to solve problems through the formation of critical thinking, understanding the dialectical nature of sustainable development (which cannot be reflected in several 
indicators on an ongoing basis; indices change depending on the actualization of various contradictions in development, though they lag behind in time from a real emerging reality).

\section{Materials and Methods}

This study dwells upon the principles of dialectical realism, which determines the paramount role of ideal values and meanings, the dependence of the path of material development on the nature of public consciousness, the system-forming role of transcendental values in the historical development (Mantatov, 2013). According to dialectical realism, the goal of the development of a socio-natural system is to strive for an unattainable ideal, which determines the possibilities of infinite enhancement on the one hand, and, on the other hand, through the dynamic development of understanding of goals for the formation of conditions for sustainable development, preventing destruction and opportunities for one-sided development.

Based on unlimited freedom and the desire to maximize the satisfaction of the materialistic desires of society, capitalism leads to self-destruction of the system, since the proclaimed ideals contradict the true ones, as well as life, the most important goal and value of being (Galbraith, 2009). Quantitative development indices, a reflection of the capitalist worldview, orientate the development of civilization following principles that contradict the objective circumstances of the limited ecological capacity of the biosphere and the dependence of humankind on the condition of the environment.

Overcoming the previously existing worldview concepts that oppose the interests of man and nature, suggesting the need for competition between different countries for resources, between people for the possibility of satisfying material needs, requires reliance on the legal mechanism for regulating public relations. The coercive power of the state ensures the enforcement of the rule of law; has greater flexibility and controllability in comparison with the norms of morality, traditions, and customs.

\section{Effectiveness and Strategic Development}

\subsection{Strategic development efficiency}

Reliance on a single development strategy is necessary to ensure comprehensive regulation of public relations. An eco-effective development strategy for the state and the enterprise has some characteristic features. For the enterprise, the effective implementation of the goals of strategic development involves obtaining the maximum economic result with minimal use of resources (Ermolina,2013). In this case, one can distinguish two aspects: the efficiency of using a particular resource and the efficiency of the processes being implemented (during which resources are used). Resource efficiency is revealed in the system of quantitative indicators: productiveness, productive capacity, cost-effectiveness. Operational (procedural) effectiveness is determined by the degree of achievement of the goals set, effectiveness of the selected measures, rationality of the resource use.

Environmental performance indicators should reflect: the efficiency factor of the entire system (energy efficiency), the coefficient of harmful effects of the system (technological 
efficiency), "environmental cleanliness of the final product" (ecological efficiency) (Artyukhov \& Martynov, 2010).

Extrapolation of the concept of the strategic enterprise development effectiveness allows us to determine ecological efficiency as the practical compliance of the implemented state (regional) policy with the goals of sustainable development and as the highest minimization of the use of natural resources while striving to obtain the most significant economic benefits.

The ability to adequately assess the eco-efficiency of the economy contributes to the transition from the extensive stage of development, where the region acts as a raw materials appendage, to the innovative stage, which involves the development of its own scientific and technological potential serving as the basis for sustainable development of the territory.

\subsection{Assessment of the strategic development efficiency}

The quantitative indicators used to assess the efficiency of the state (regional) strategy are somewhat one-sided in nature as they do not reflect all systemic aspects of development:

- The gross domestic product, based on the indicators of production of goods and services in the country (region) for the calculation period does not allow to consider environmental aspects fully (Kelly, 1991);

- The Human Development Index, combining economic and social aspects with environmental ones (the level of carbon dioxide emissions into the atmosphere, the level of natural resources consumption, the ecological footprint from the economic activity) (UNDP, 1990), faces the problem of eroding individual development contradictions when calculating the overall indicator. For instance, high economic indicators can compensate for high environmental risks and low satisfaction of social interests. Additionally, in terms of environmental impact, carbon dioxide emissions are not directly correlated with other aspects of environmental quality: loss of biodiversity, higher nitrate and phosphate levels in water bodies, reduced soil fertility, deforestation, and some others.

J. Hickel sees the solution to this problem in the separation of the earnings yield from the ongoing economic activities and the negative effect indicator on the cost of the region's environment reclamation (Hickel, 2019). A.S. Martynov and V.V. Artyukhov adhere to a similar approach in assessing the eco-efficiency of the enterprise: one should measure the ratio of the indicators of produced useful products to the entire amount of substance-energy spent (Artyukhov \& Martynov, 2010). In fact, we are talking about calculating the efficiency factor of the system, assessing the actual ratio of positive and negative effects of ongoing economic activities.

Measuring the environmental efficiency of economic activity by determining the ratio of gross indicators allows us to determine:

- nature management efficiency (production and consumption routes);

- environmental impact (whether it is really beneficial to develop these resources in a given area, how dangerous the medium and long term consequences are);

- impact on the living standards of the population.

Nevertheless, it is possible to really assess the actual environmental damage only after a 
considerable time. Quantitative indicators aim to solve current problems and problems in progress, but they do not form a dialectical understanding of the strategy of sustainable development for an indefinitely long period. Conversely, qualitative criteria contribute to resolving current development contradictions and are the basis for the formation of consciousness relevant to sustainable development on a long-term basis.

\subsection{Concept of the eco-efficient development strategy}

To ensure sustainable development for an indefinitely long term, we need reliance on qualitative (value) development criteria. As the main ones, we single out "environmental justice" and "recognition of the intrinsic value of nature," which contribute to the formation of a noospheric worldview (Gunzenova, 2019):

- environmental justice is intertwined with social justice and presupposes the equality of environmental rights (for a favorable living environment and reliable information about its condition, clean drinking water, clean air) and responsibilities, regardless of race, gender, nationality, economic and social status, and other distinctive features of the person. Environmental justice sets a balance in social relations in the field of environmental issues. Thus, the goals of economic development do not condone the infringement of the environmental and social rights of more vulnerable layers of the population;

- recognition of the intrinsic value of nature allows us to establish a balance at the level of socio-natural relations, where, through respect for non-human forms of life, economic development is ensured within the ecological capacity of the biosphere. The balance established by nature itself is a prerequisite for human life. With its significant violation, the survival of humankind is put in jeopardy (poisoned air, water, and soil, reduction in species diversity, melting glaciers, global warming, adaptation to new conditions, and, accordingly, the emergence of new types of viruses and bacteria fatal to humans). Due to the delayed nature of the negative consequences, with a limited worldview, a person is unable to realize the magnitude of the consequences of violating the current balance in nature. Through recognition of the intrinsic value of nature and concern for its conservation, a way of thought and action is formed aimed at maintaining the conditions for the survival of man as a biological species.

\section{The Development Strategy of the Baikal Region}

\subsection{Contradictions in the strategic development of the Baikal region}

The strategy of socio-economic development of the Far East and the Baikal region until 2025 as a threat to sustainable regional development notes "a low degree of diversification and innovativeness of the regional economy, which has a pronounced resource focus with a low degree of processing of natural resources". Orientation to natural rent in the structure of the state economy is directly interconnected with emerging socio-economic and subsequent environmental problems of social development. Instead of creating new assets and efficiently spending the funds received, innovative development, quality education of the local population, expanding social guarantees, the territory receives the opposite effect, expressed in corruption, environmental disasters, impoverishment of the majority of the population. 
The ecological crisis as a result of an environmentally inefficient development strategy manifests itself, including in the reproduction of filamentous algae spirogyra. As studies of limnologists have shown, the reason for this phenomenon is the excess intake of biogenic elements such as nitrogen and phosphorus into the lake (Timoshkin et.al. 2014). Industrial and domestic effluents entering Baikal from poorly functioning or dilapidated sewage treatment plants located in coastal settlements affect the hydrochemical parameters of Baikal water. The solution to this problem involves the transfer of industrial activity polluting the ecology of the lake to a safe distance from the lake, along with environmental restrictions on the activities of local residents. However, the introduction of such measures may give rise to economic problems for the local population. The issue of establishing a balance between economic and environmental interests requires a comprehensive worldview, which can be carried out on the basis of applying qualitative criteria to assess the development of the territory.

The modern monitoring system of Lake Baikal provides for tracking only a limited number of hydrophysical, hydrochemical and hydrobiological parameters, it is unable to quickly diagnose environmental emergencies in the coastal zone of the lake.

The Strategy for Socio-Economic Development until 2025 notes the need to take into account "the danger of environmental pollution from resource sectors and the destruction of natural ecosystems in areas of increased concentration of economic activity", which correlates with the main goal of sustainable development - a harmonious combination of economic, environmental and social needs. On the other hand, the Strategy sets quite contradictory goals that carry potential danger:

- the implementation of large-scale energy projects, when the guarantee of a sustainable, economically viable and environmentally friendly energy is the decentralization of the region's energy system and the use of renewable energy sources;

- the growth of export of extracted raw materials and the implementation of large-scale projects for the extraction, supply and processing of hydrocarbon fuels, when a resourceoriented economy impedes the development of the economy of the region and the country as a whole and is associated with an increase in the cost of solving environmental problems;

- development of the forestry complex without taking into account the fact that the conservation of the last remaining undeveloped forests in the Baikal basin is a factor necessary to maintain a stable flow of the rivers feeding Baikal and to preserve the unique ecosystem of the lake basin;

- many large industrial projects and linear facilities mentioned in the Strategy are planned for deployment in the southern (steppe) territories, while there are no issues of protecting and protecting the ecology of the steppe and forest-steppe territories.

At the same time, environmentally efficient ways of developing the region (sustainable tourism, protection and support of small business, development of renewable energy) were not adequately addressed. The tourist and recreational specialization of the Baikal region is experiencing difficulties associated with the preservation of the natural environment and ecosystems with an increasing anthropogenic load from uncontrolled tourism, industry, and extractive industries. Ecotourism involves the introduction of the latest technologies for waste processing, the establishment of large fines, administrative and criminal penalties for violating the environmental standards of Lake Baikal. All this 
should stem from the understanding of the primary importance of preserving the region's ecology, since without clean drinking water, fertile land, preservation of natural biodiversity, positive economic indicators are temporary in the case of irreparable harm to the environment.

The contradictions contained in the strategy under consideration prove the lack of a single understanding of the essence of the concept of sustainable development. Reliance solely on current economic and limited environmental indicators is not enough; a balanced approach to managing strategic development is needed.

Environmental restrictions should be an incentive for the development of innovative entrepreneurship, environmentally friendly technologies, scientific and educational potential, capable of ensuring the economic prosperity of the region with a careful attitude to the natural environment.

Ignoring the issue of bio-capacity of the natural environment, the lack of control and a sufficient degree of organization of the tourist flow in an effort to maximize economic profit, jeopardizes the fragile ecosystem of Lake Baikal.

\subsection{Features of the development of the Baikal region}

The presence of a natural object of global importance, undisturbed ecosystems, ethnocultural traditions of indigenous peoples preserved over the centuries, interethnic and interfaith balance, unique geographical location at the crossroads of East and West suggest significant opportunities for the sustainable development of the region (high tourist and recreational potential of the territory, traditions, and customs relevant to sustainable development, environmental restrictions on economic activity and so on) (Saktoev \& Mantatov, 2015).

On the other hand, the significant resource potential of the Baikal region, the presence of technologically and economically developed neighbors, such as China, South Korea, and Japan while the level of development of the territory itself remains low, the virtual absence of an effective innovation policy, threaten us with the "natural-resource curse" effect.

The development criteria laid down in the strategy determine the path along which the Baikal region will develop. These guidelines focused on improving economic indicators without taking into account the environmental aspects that are unable to provide sustainable development. On the contrary, they cause an increase in contradictions between short-term and long-term goals, between the socio-economic interests of the local population and the generation of excess profits from the exploitation of resource potential, true values, and those imposed by the consumer society).

The analysis of the implementation of the Strategy for socio-economic development of the Far East and the Baikal region for the period until 2025 contains (Decree of the Government of the Russian Federation of December 28, 2009 N 2094-r; On the implementation of the Strategy for the socio-economic development of the Far East and the Baikal region for the period until 2025):

- assessment of the environmental situation based on the indicators of captured and neutralized air pollutants, which does not reflect the full picture of the environmental impact of economic activity; 
- GRP1 indicators in relation to the average among the subjects of the Russian Federation, which does not allow us to assess the totality of economic and environmental factors for the development of the territory;

- in the structure of the GRP, the industry is growing (which includes mining activities) with a decrease in the share of the "agriculture," "construction" and suchlike sectors, thus creating the conditions for increasing the indicator of economic efficiency of the region's development while maintaining an extensive development path;

- reliance on universal integral indicators regarding issues of man-made impact (and, as a result, erosion of certain aspects of development when calculating a general single index - "if water consumption in a region is $2 \%$ of water consumption in Russia, emissions into the atmosphere are 3\%, and waste generation - 1\%, then the average level of manmade impact on these three indicators will be $2 \%$ ");

- determination of the level of environmental pollution (emissions of pollutants into the atmosphere, discharges of polluted wastewater) through the calculation of data in comparison with a single indicator for the country, which allows us to evaluate the effectiveness only in relative proportion to all-Russian indicators.

Given the absence of quality guidelines, planning and strategic documents mediating the development of the Baikal region threaten to reduce the central ecological zone of the Baikal natural territory, implement a resource-dependent model of the economy, increase the environmental burden on the territory due to uncontrolled tourist flow, lack of consistency and sequence of measures aimed at preserving Lake Baikal (Gunzenova \& Rinchinov, 2019).

\section{Conclusions}

The Russian Federation has adopted a course for sustainable development. Short-, medium- and long-term regional strategies must be adopted based on it. At the same time, indices should make it possible to track the effectiveness of the implemented policy, the degree to which the actual results are relevant to those planned.

Given the absence of systematizing qualitative development criteria, some problems may arise in this chain:

- the set strategic development goals do not correspond to the essence of sustainable development. Then the indices for assessing the efficiency of strategic development will not adequately reflect the progress in building a balanced social and natural interaction; - a flawed methodology for the formation of development indices does not allow us to assess the effects of policies fully. High indicators do not testify to the provision of conditions for the co-evolutionary development of man and nature;

- misunderstanding of the content of sustainable development instead of focusing on innovative products, creating new regional assets and ensuring social justice rests on intensified exploitation of natural resources, the unfair distribution of profits from their development and responsibility for violating the natural ecological balance of territories; - a limited understanding of sustainable development, reducing its essence to existing goals and values, which are only a stage in the endless path of dialectical social and

${ }^{1}$ Gross regional product 
natural development. Lack of flexibility and adaptability, the threat of stagnation in the development.

Analysis of the "Strategy for the socio-economic development of the Far East and the Republic of Buryatia until 2025" indicates the relevance of the problems mentioned above. Contrary to using quantitative development indices as benchmarks, the reliance on the concept of ecological efficiency has several advantages:

- it forms an integrated picture of the world;

- it develops the ability to analyze and make environmentally sound decisions independently;

- it contributes to the awareness of the dialectical nature of the development of the socio-natural system and the relative nature of the development indices used in a particular period;

- it provides systematic planning of transformations and a single focus on strategic development.

\section{References}

Artyukhov, V.V., Martynov, A.S. (2010) Methodology for assessing the environmental and energy efficiency of the Russian economy, Moscow: Interfax.

Decree of the Government of the Russian Federation of December 28, 2009 N 2094-r "On the Strategy for the socio-economic development of the Far East and the Baikal region for the period until 2025" from 28.12.2009 № 2094-p [Online]. Available at: http://www.garant.ru/products/ ipo/prime/doc/6632462/\#ixzz5dD6I roE2 (Accessed 08.12.2019).

Ermolina, L.V. (2013) 'Economic maintenance of the category of "effectiveness". The concept of strategic effectiveness', Basis of economy, governance and law, 2(8) [Online]. Available at: https://cyberleninka.ru/article/n/ekonomicheskoe-soderzhanie-kategorii-effektivnost-ponyatiestrategicheskoy-effektivnosti (Accessed 24.01.2020).

Gunzenova, K.V., Rinchinov, K.A. (2019) 'Planning and strategic development of the Baikal region: problems and prospects'. Human Progress, 5(1) [Online]. Available at: http://progresshuman.com/images/2019/Tom5_1/Gunzenova.pdf, вободный. DOI 10.34709/IM.151.1 (Accessed 12.12.2019).

Gunzenova, K. (2019). Ecological Efficiency" as a Value Criterion of the Sustainable Development Strategy. European Journal of Sustainable Development, 8(2), 217. https://doi.org/10.14207/ejsd.2019.v8n2p217.

Hickel, J. (2019). 'The Sustainable Development Index: Measuring the ecological efficiency of human development in the Anthropocene'. Ecological Economics [Online]. Available at: 167.10.1016/j.ecolecon.2019. 05.011 (Accessed 23.01.2020).

Galbraith, J.K. (2009) Economics of innocent deception: the truth of our time, Moscow: Publishing house "Europe".

Kelly, I. 'The human development index: handle with care', Popul. Dev. Rev., 1991, 17 (2), pp. 315-324.

Mantatov, V.V. (2013) 'Phylosophical and axiological foundations of socialist idea (in the context of sustainable development)'. Eurasia and world, 1(1), pp.64-72.

On the implementation of the Strategy for the socio-economic development of the Far East and the Baikal region for the period until 2025, approved by order of the Government of the Russian Federation of December 28, 2009 No. 2094-r [Online]. Available at: http://old.economy.gov.ru/ wps/wcm/connect/ce59fb6a-5420-4f97-ad02-58bad3dba115/

report_dvb.pdf?MOD=AJPERES\& $\quad$ CACHEID=ce59fb6a-5420-4f97-ad02-58bad3dba115 (Accessed 08.12.2019).

Order of the Government of the Russian Federation "On the Strategy of Socio-Economic Development of the Far East and the Baikal Region for the Period up to 2025”, 28.12.2009 № 2094-r [Online]. URL: http://www.garant.ru/products/ipo/ prime/doc/6632462/\#ixzz5dD6IroE2 (Accessed: 11 April 2020). 
Saktoev, V.E., Mantatov, V.V., Alekseev, S.G. (2015). 'An innovative model of sustainable development of the Baikal region: prerequisites and prospects', Science, Technology and Education, 11 (17), 65-70.

Timoshkin, O.A., Malnik, V.V., Sakirko, M.V., Boedeker C. 'Ecological Crisis on Lake Baikal: Scientists Diagnose', First-hand Science, 5 (59), 2014, pp. 74-91.

UNDP. Human Development Report. 1990 [Online]. Available at: http://hdr.undp.org/sites/default/files/reports/219/hdr_1990_en_complete_nostats.pdf (Accessed 22.12.2019). 